\title{
Synthesis of 2-amino-4H-chromene derivatives under microwave irradiation and their antimicrobial activity
}

\author{
NIRAV K SHAH, NIMESH M SHAH, MANISH P PATEL and RANJAN G PATEL* \\ Department of Chemistry, Sardar Patel University, Vallabh Vidyanagar 388 120, India \\ e-mail: patelranjanben@yahoo.com
}

MS received 23 January 2012; revised 15 November 2012; accepted 21 January 2013

\begin{abstract}
Libraries of 2-amino-4H-chromenes, were efficiently synthesized via one-pot, three-component reactions of 5-chloro-3-methyl-1-aryl-4,5-dihydro-1 $H$-pyrazole-4-carbaldehyde (1a-c), 2-naphthols (2a-f) and malononitrile in the presence of catalytic amount of ammonium acetate under microwave irradiation. The protocol offers rapid synthesis of structurally diverse 2 -amino- $4 H$-chromenes for biological screening. All the synthesized compounds were evaluated for their antimicrobial activity, and several compounds exhibited moderate to potent antimicrobial activity.
\end{abstract}

Keywords. Multicomponent reactions (MCRs); pyrazole; naphthols.

\section{Introduction}

Design of highly efficient chemical reaction sequences that provide maximum structural complexity and diversity with a minimum number of synthetic steps to assemble compounds with interesting properties is a major challenge of modern drug discovery. ${ }^{1}$ Recently, multicomponent reactions have emerged as a highly valuable synthetic tool in the context of modern drug discovery. Atom economy and convergent character, simplicity of a one-pot procedure, possible structural variations, accessible complexity of the molecules, and very large number of accessible compounds are among the described advantages of multicomponent reactions. ${ }^{2}$ Thus, they are perfectly amenable to automation for combinatorial synthesis. ${ }^{3}$

2-Aminochromenes are an important class of heterocyclic compounds having significant biological activities. During the last decade, such compounds have shown interesting pharmacological properties including, antimicrobial, ${ }^{4}$ antiviral, ${ }^{5,6}$ mutagenicity, ${ }^{7}$ antiproliferative,${ }^{8}$ sex hormone, ${ }^{9}$ antitumour, ${ }^{10}$ cancer therapy, ${ }^{11,12}$ and central nervous system activities. ${ }^{13}$ 2-Aminochromenes were also used as biodegradable agrochemicals and components of many natural products. ${ }^{14}$

*For correspondence
Pyrazole derivatives are well-established in the literature as important biologically effective heterocyclic compounds. These derivatives are the subject of many research studies due to their widespread potential pharmacological activities such as antiinflammatory, antipyretic, antimicrobial, antiviral, antitumour, anticonvulsant, antihistaminic and antidepressant activities. ${ }^{15}$ Widely prescribed anti-inflammatory pyrazole derivatives, celecoxib ${ }^{16}$ and deracoxib ${ }^{17}$ are selective COX-2 inhibitors with reduced ulcerogenic side effects.

Microwave-assisted organic synthesis has rapidly gained popularity since it accelerates a variety of synthetic transformations, ${ }^{18}$ and has prominent advantages of short reaction time and high yield. ${ }^{19}$

Thus, it goes without saying that the use of atom-economical multicomponent reactions (MCRs), together with the employment of energy-efficient microwave irradiation (MW), must be considered to be a facile and effective synthetic strategy of heterocyclic compounds with important bioactivities in the sense that the combination in itself offers greater potential than two parts in isolation.

With the aim to develop more efficient synthetic processes and minimized byproducts, and in continuation of our recent interest in the construction of heterocyclic scaffolds with antimicrobial activity, ${ }^{20-22}$ we herein describe a practical, inexpensive and rapid MW-promoted method for synthesis of 2-amino- $4 \mathrm{H}$ chromenes derivatives via MCRs of 3-methyl-1-phenyl5-chloro-4-pyrazolocarbaldehyde (1a-c), 2-naphthols $(\mathbf{2 a}-\mathbf{f})$ and malononitrile in the presence of ammonium 
acetate in ethanol (EtOH). It is an efficient and promising method to construct the 2 -amino- $4 H$-chromene skeleton.

\section{Experimental}

\subsection{Materials and methods}

Solvents used were of analytical grade. All melting points were taken in open capillaries and are uncorrected. Thin-layer chromatography (TLC, on aluminium plates precoated with silica gel, 60F254, $0.25 \mathrm{~mm}$ thickness) (Merck, Darmstadt, Germany) was used for monitoring the progress of all reactions, purity and homogeneity of the synthesized compounds; eluent-hexane:ethyl acetate 6:4. UV radiation and/or iodine were used as visualizing agents. Elemental analysis $(\% \mathrm{C}, \mathrm{H}, \mathrm{N})$ was carried out with a PerkinElmer 2400 series-II elemental analyser (Perkin-Elmer, USA) and all compounds were within $\pm 0.4 \%$ of calculation. IR spectra were recorded in $\mathrm{KBr}$ pellet on a Perkin-Elmer Spectrum GX FT-IR Spectrophotometer (Perkin-Elmer, USA), and only characteristic peaks were reported in $\mathrm{cm}^{-1} \cdot{ }^{1} \mathrm{H}-\mathrm{NMR}$ and ${ }^{13} \mathrm{C}$-NMR spectra were recorded in DMSO- $\mathrm{d}_{6}$ on a Bruker Avance 400F $(\mathrm{MHz})$ Spectrometer (Bruker Scientific Corporation
Ltd., Switzerland) using solvent peak as internal standard at 400 and $100 \mathrm{MHz}$ respectively. Chemical shifts were reported in parts per million (ppm).

2.2 General procedure for the synthesis of 5-chloro-3methyl-1-aryl-4,5-dihydro-1H-pyrazole-4-carbaldehyde $(\mathbf{1 a}-\mathbf{c})$

5-Chloro-3-methyl-1-aryl-4,5-dihydro- $1 \mathrm{H}$-pyrazole-4carbaldehyde was prepared, according to literature procedure ${ }^{23}$ by Vilsmeier-Haack reaction of 3-methyl1-aryl-1 $H$-pyrazol-5(4H)-one.

\subsection{General procedure for the synthesis of 2-amino- $4 H$-chromenes derivatives (3a-r)}

A mixture of 5-chloro-3-methyl-1-aryl-4,5-dihydro$1 \mathrm{H}$-pyrazole-4-carbaldehyde $\quad(1 \mathrm{mmol}) \quad(\mathbf{1 a}-\mathbf{c})$, 2-naphthols (1 mmol) (2a-f) and malononitrile (1 mmol) and ammonium acetate $(0.2 \mathrm{mmol}, 20 \mathrm{~mol} \%)$ in EtOH $(5 \mathrm{~mL})$ was thoroughly mixed and irradiated at $300 \mathrm{~W}$ MW for 5-6 min (the reactions were monitored by TLC). After completion, the reaction mixture was cooled to room temperature, and the solid formed was collected by filtration and crystallized from the appropriate solvent. Physical, analytical and spectroscopic

Table 1. Antimicrobial activity of compounds (3a-r).

\begin{tabular}{|c|c|c|c|c|c|c|}
\hline \multirow[b]{3}{*}{ Compound } & \multicolumn{6}{|c|}{ Zone of inhibition (in mm) } \\
\hline & \multicolumn{3}{|c|}{ Antibacterial activity } & \multicolumn{3}{|c|}{ Antifungal activity } \\
\hline & E. coli & B. substilis & S. aureus & F. oxysporum & A. niger & R. oryzae \\
\hline $\mathbf{3 a}$ & 19 & 24 & 19 & 15 & 18 & 25 \\
\hline $\mathbf{3 b}$ & 16 & 17 & 24 & 14 & 24 & 20 \\
\hline $3 c$ & 20 & 24 & 20 & 20 & 19 & 17 \\
\hline 3d & 24 & 18 & 18 & 15 & 23 & 17 \\
\hline $3 \mathbf{e}$ & 22 & 20 & 20 & 15 & 16 & 25 \\
\hline 3f & 20 & 25 & 23 & 16 & 18 & 22 \\
\hline $3 g$ & 17 & 23 & 16 & 13 & 24 & 20 \\
\hline $3 \mathbf{h}$ & 17 & 19 & 25 & 15 & 18 & 25 \\
\hline $3 \mathbf{i}$ & 22 & 19 & 18 & 21 & 24 & 20 \\
\hline 3j & 18 & 24 & 17 & 20 & 20 & 19 \\
\hline 3k & 25 & 20 & 20 & 17 & 19 & 25 \\
\hline 31 & 20 & 19 & 24 & 13 & 18 & 20 \\
\hline $3 \mathrm{~m}$ & 25 & 18 & 19 & 14 & 19 & 24 \\
\hline $3 n$ & 20 & 23 & 20 & 12 & 20 & 18 \\
\hline 30 & 19 & 17 & 25 & 15 & 25 & 18 \\
\hline $3 p$ & 24 & 20 & 20 & 20 & 24 & 19 \\
\hline $3 q$ & 20 & 25 & 17 & 12 & 20 & 23 \\
\hline $3 r$ & 25 & 19 & 24 & 14 & 17 & 20 \\
\hline Ampicillin & 28 & 30 & 30 & - & - & - \\
\hline Ciprofloxacin & 35 & 34 & 33 & - & - & - \\
\hline Griseofulvin & - & - & - & 26 & 28 & 30 \\
\hline
\end{tabular}


characterization data of the synthesized compound $\mathbf{3 a}$ is given below:

2.3a 3-Amino-1-(5-chloro-3-methyl-1-phenyl-1H-pyrazole4-yl)-2-cyano-N-phenyl-1H-benzo[f]chromene-5carboxamide (3a): Yield 85\%; m.p.: 225-226 $6^{\circ} \mathrm{C}$ IR $\left(\mathrm{KBr}, v, \mathrm{~cm}^{-1}\right)$ : $3485 \& 3290$ (asym. \& sym. stretching of $\mathrm{NH}_{2}$ ), 2228 ( $\mathrm{CN}$ str.), $1650\left(\mathrm{C}=\mathrm{O}\right.$ str.); ${ }^{1} \mathrm{H}$ nuclear magnetic resonance (NMR) (400 MHz, DMSO- $d_{6}$ ): $\delta 2.36\left(\mathrm{~s}, 3 \mathrm{H}, \mathrm{CH}_{3}\right), 5.24(\mathrm{~s}, 1 \mathrm{H}, \mathrm{CH}), 7.08(\mathrm{~s}, 2 \mathrm{H}$, $\left.\mathrm{NH}_{2}\right), 7.12-8.21(\mathrm{~m}, 15 \mathrm{H}, \mathrm{Ar}-\mathrm{H}), 8.45(\mathrm{~s}, 1 \mathrm{H}, \mathrm{NH})$; ${ }^{13} \mathrm{C}$ NMR (100 MHz, DMSO- $\left.d_{6}\right) \delta: 12.50\left(\mathrm{CH}_{3}\right)$, 28.70 (chromene C4), 55.75 ( $\underline{\mathrm{C}}-\mathrm{CN}), 114.12,118.17$, $122.78,123.11,123.25,124.88,124.97,125.55$, $126.15,127.17,128.71,128.98,129.16,129.73$, $130.25,131.46,132.81,135.25,137.12,138.33$, 145.02, 147.37, 158.81 (Ar-C, 23C), $159.25(\mathrm{C}=\mathrm{O})$; MS $(m / z): 532\left(\mathrm{M}^{+}\right)$; Anal. Calcd. for $\mathrm{C}_{31} \mathrm{H}_{22} \mathrm{ClN}_{5} \mathrm{O}_{2}$ (531.99 g/mol): C, 69.99; H, 4.17; N, 13.16. Found: C, $69.91 ; \mathrm{H}, 4.22 ; \mathrm{N}, 13.12$.

\subsection{Antibacterial activity}

In vitro antimicrobial activity was carried out against $24 \mathrm{~h}$ old cultures of three bacteria and three fungi by disc diffusion method. ${ }^{24,25}$ Compounds (3a-r) have been tested for their antibacterial activity against Escherichia coli as Gram-negative bacteria and Bacillus subtilis and Bacillus cereus as Gram-positive bacteria and antifungal activity against Aspergillus niger, Fusarium oxysporum and Rhizopus. Nutrient agar and potato dextrose were used to culture the bacteria and fungus, respectively. The compounds were tested at $1000 \mathrm{ppm}$ in Dimethylformamide (DMF) solution. Ciprofloxacin, Ampicillin and Griseofulvin were used as standards for comparison of antibacterial and antifungal activities, respectively. Inhibition was recorded by measuring the diameter of the inhibition zone at the end of $24 \mathrm{~h}$ for bacteria at $35^{\circ} \mathrm{C}$ and $48 \mathrm{~h}$ for fungus at $28^{\circ} \mathrm{C}$. The results are summarized in table 1 .

\section{Results and discussion}

Synthesis of the target compounds is outlined in scheme 1. The required starting material, 5-chloro-3methyl-1-aryl-4,5-dihydro- $1 H$-pyrazole-4-carbaldehyde was prepared by Vilsmeier-Haack reaction of 1-aryl-3-methyl-1 $H$-pyrazol-5(4H)-one which leads to chloroformylation to afford 5-chloro-3-methyl-1-aryl4,5-dihydro- $1 H$-pyrazole-4-carbaldehyde according to literature procedure. ${ }^{23}$ The one-pot three-component condensation reaction of 5-chloro-3-methyl-1-aryl4,5-dihydro- $1 H$-pyrazole-4-carbaldehyde $(\mathbf{1 a}-\mathbf{c})$, 2naphthols (2a-f) and malononitrile proceeded smoothly in ethanol under MW irradiation in the presence of ammonium acetate as a catalyst to give the corresponding 2-amino- $4 \mathrm{H}$-chromene (3a-r) derivatives in good to excellent yields.

To choose the most appropriate medium in this heterocyclization reaction, the $\mathrm{MW}$-assisted reaction of 5-chloro-3-methyl-1-aryl-4,5-dihydro- $1 H$-pyrazole4-carbaldehyde (1a-c), 2-naphthols (2a-f) and malononitrile, was examined in Acetic acid (HOAc), glycol, tetrahydrofuran (THF), DMF and EtOH as solvents, respectively under $\mathrm{MW}$ at the maximum power of $350 \mathrm{~W}$. The reaction in EtOH resulted in higher yields and shorter reaction time than others. Therefore, EtOH was chosen as the solvent of this reaction. Moreover, to further improve the reaction yields, different solvents such as ammonium acetate, $\mathrm{NaOH}, \mathrm{K}_{2} \mathrm{CO}_{3}$, dimethyl amino pyridine (DMAP), $\mathrm{Et}_{3} \mathrm{~N}$ and piperidine were examined in ethanol. Ammonium acetate afforded the target product $\mathbf{3 a}$ in $85 \%$ yield. So, ammonium acetate was chosen for all further MW assisted reactions. The base optimization for yields is listed in table 2 .

We propose a mechanism of the ammonium acetate-catalysed condensation as shown in scheme 2 . Condensation of 5-chloro-3-methyl-1-aryl-4,5-dihydro$1 \mathrm{H}$-pyrazole-4-carbaldehyde (1a-c), 2-naphthols (2a-f) and malononitrile may occur by a mechanism of Knoevenagel condensation, Michael addition, intramolecular cyclization and isomerization. Initially, Knoevenagel condensation of 5-chloro-3-methyl-1aryl-4,5-dihydro- $1 H$-pyrazole-4-carbaldehyde $(\mathbf{1 a - c})$ and malononitrile by the action of ammonium acetate to afford a cyanocinnamonitrile derivative 4 . Then, the proton of 2-naphthols (3a-f) is abstracted by ammonium acetate to form intermediate $\mathbf{5}$. Michael addition of intermediate $\mathbf{5}$ on $\mathbf{4}$ leads to the formation of $\mathbf{6}$, followed by cyclization and isomerization, affords the corresponding products (3a-r) (scheme 2).

\subsection{Spectroscopic analysis}

The structures of newly synthesized compounds were elucidated by combined use of IR, ${ }^{1} \mathrm{H}$ and ${ }^{13} \mathrm{C}$ NMR, mass spectral data and elemental analysis. Absorption bands for compounds $(\mathbf{3} \mathbf{a}-\mathbf{r})$ in IR-spectra were observed in the range of $2200-2236 \mathrm{~cm}^{-1}$, corresponding to $\mathrm{C} \equiv \mathrm{N}$. The $\mathrm{NH}_{2}$ stretching and $\mathrm{C}=\mathrm{O}$ stretching vibrations for all the compounds were observed in range of $3280-3495 \mathrm{~cm}^{-1}$ and $1635-1675 \mathrm{~cm}^{-1}$, respectively. The ${ }^{1} \mathrm{H}$ NMR spectrum of compounds (3a-r) indicated the presence of one singlet in the range $\delta 5.24-5.56 \mathrm{ppm}$ 


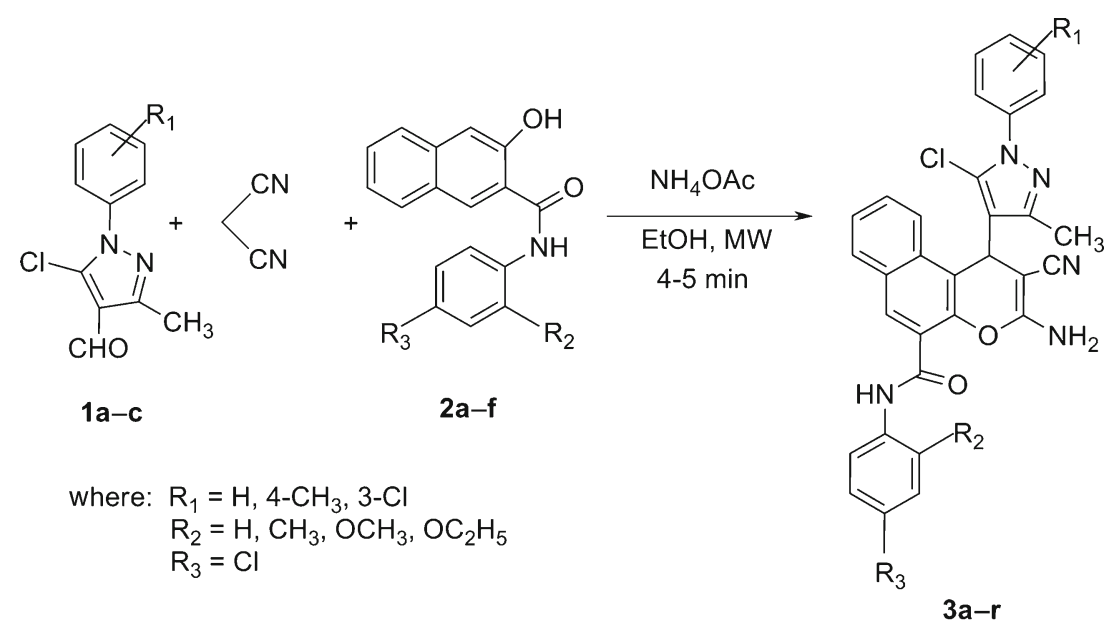

\begin{tabular}{c|c|c|c|c|c|c|c}
\hline Compound & $\mathbf{R}_{\mathbf{1}}$ & $\mathbf{R}_{\mathbf{2}}$ & $\mathbf{R}_{\mathbf{3}}$ & Compound & $\mathbf{R}_{\mathbf{1}}$ & $\mathbf{R}_{\mathbf{2}}$ & $\mathbf{R}_{\mathbf{3}}$ \\
\hline $\mathbf{3 a}$ & $\mathrm{H}$ & $\mathrm{H}$ & $\mathrm{H}$ & $\mathbf{3 j}$ & $4-\mathrm{CH}_{3}$ & $\mathrm{OC}_{2} \mathrm{H}_{5}$ & $\mathrm{H}$ \\
$\mathbf{3 b}$ & $\mathrm{H}$ & $\mathrm{CH}_{3}$ & $\mathrm{H}$ & $\mathbf{3 k}$ & $4-\mathrm{CH}_{3}$ & $\mathrm{Cl}$ & $\mathrm{H}$ \\
$\mathbf{3 c}$ & $\mathrm{H}$ & $\mathrm{OCH}_{3}$ & $\mathrm{H}$ & $\mathbf{3 l}$ & $4-\mathrm{CH}_{3}$ & $\mathrm{CH}_{3}$ & $\mathrm{Cl}$ \\
$\mathbf{3 d}$ & $\mathrm{H}$ & $\mathrm{OC}_{2} \mathrm{H}_{5}$ & $\mathrm{H}$ & $\mathbf{3 m}$ & $3-\mathrm{Cl}$ & $\mathrm{H}$ & $\mathrm{H}$ \\
$\mathbf{3 e}$ & $\mathrm{H}$ & $\mathrm{Cl}$ & $\mathrm{H}$ & $\mathbf{3 n}$ & $3-\mathrm{Cl}$ & $\mathrm{CH}_{3}$ & $\mathrm{H}$ \\
$\mathbf{3 f}$ & $\mathrm{H}$ & $\mathrm{CH}_{3}$ & $\mathrm{Cl}$ & $\mathbf{3 0}$ & $3-\mathrm{Cl}$ & $\mathrm{OCH}_{3}$ & $\mathrm{H}$ \\
$\mathbf{3 g}$ & $4-\mathrm{CH}_{3}$ & $\mathrm{H}$ & $\mathrm{H}$ & $\mathbf{3 p}$ & $3-\mathrm{Cl}$ & $\mathrm{OC}_{2} \mathrm{H}_{5}$ & $\mathrm{H}$ \\
$\mathbf{3 h}$ & $4-\mathrm{CH}_{3}$ & $\mathrm{CH}_{3}$ & $\mathrm{H}$ & $\mathbf{3 q}$ & $3-\mathrm{Cl}$ & $\mathrm{Cl}$ & $\mathrm{H}$ \\
$\mathbf{3 i}$ & $4-\mathrm{CH}_{3}$ & $\mathrm{OCH}_{3}$ & $\mathrm{H}$ & $\mathbf{3 r}$ & $3-\mathrm{Cl}$ & $\mathrm{CH}_{3}$ & $\mathrm{Cl}$
\end{tabular}

Scheme 1. Synthetic pathway for the 2-amino- $4 H$-chromenes.

of $\mathrm{C}_{4} \mathrm{H}$ proton. Moreover, the ${ }^{1} \mathrm{H}$ NMR spectrum of all the compounds showed broad singlet in the range of $\delta 7.04-7.13 \mathrm{ppm}$ due to the $\mathrm{NH}_{2}$ protons and one singlet in the range $\delta 8.43-9.41 \mathrm{ppm}$ of $\mathrm{NH}$ proton. In the ${ }^{13} \mathrm{C}$ NMR spectra of $(\mathbf{3 a}-\mathbf{r})$, the signals assigned to $\mathrm{C} 4 \delta 28.14-28.93 \mathrm{ppm}$ and to the carbonyl group $\delta$ 195.45-195.65 were the most relevant features. The signal at around $\delta 55.16-55.93 \mathrm{ppm}$ is assigned to carbon attached to carbonitrile. The obtained elemental

Table 2. Base optimization for the synthesis of $\mathbf{3 a}$ under microwave irradiation.

\begin{tabular}{lc}
\hline Base & Yield $^{\mathrm{a}} \%$ \\
\hline $\mathrm{NaOH}$ & 58 \\
$\mathrm{~K}_{2} \mathrm{CO}_{3}$ & 70 \\
$\mathrm{DMAP}_{\mathrm{Et}} \mathrm{N}$ & 56 \\
Piperidine & 76 \\
Ammonium acetate & 80 \\
\end{tabular}

${ }^{\mathrm{a}}$ Isolated yields analysis values are in good agreement with theoretical data. Mass spectra of the title compounds gave $[\mathrm{M}+\mathrm{H}]^{+}$ peaks in agreement with their exact mass or molecular weight.

\subsection{Antimicrobial activity}

A reviewing antibacterial activities of $4 H$-chromenes (3a-r) (table 1) assay indicated that compounds displayed variable inhibitory effects on the growth of the tested Gram-positive and Gram-negative bacterial strains. In this view, against $E$. coli analogues $\mathbf{3 k}, \mathbf{3 m}$, 3r (Zone of inhibition 25), 3d, 3p (Zone of inhibition 24), 3e and 3i (Zone of inhibition 22) exhibited good antibacterial activity compared to the standard ampicillin (Zone of inhibition 28). With regard to activity against $B$. subtilis, good inhibitory effects was displayed by compounds 3f, 3q (Zone of inhibition 25), 3a, 3c, 3j (Zone of inhibition 24), 3g and 3n (Zone of inhibition 23) relative to ampicillin (Zone of inhibition 30). Inhibiting Gram-positive bacteria Staphylococcus 

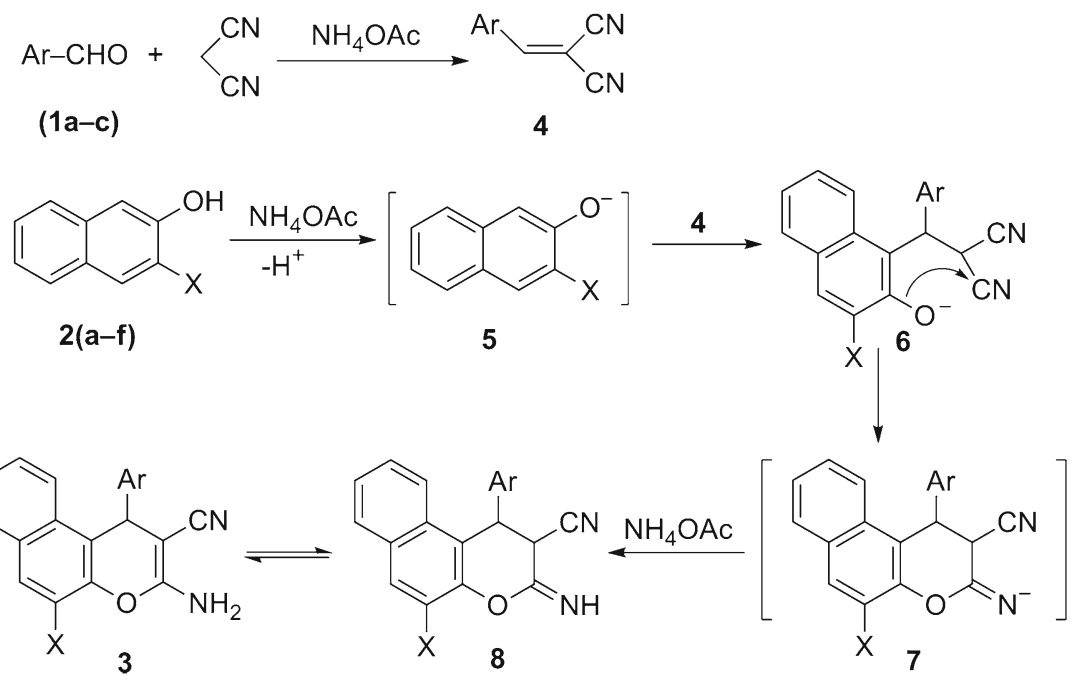

$\mathrm{Ar}=5$-Chloro-3-methyl-1-aryl-4,5-dihydro- $1 \mathrm{H}$-pyrazole-4-carbaldehyde
$\mathrm{X}=$ Substituted phenylcarboxamide derivatives

Scheme 2. Plausible mechanism for the formation of 2 -amino- $4 H$-chromene derivatives (3a-r).

aureus compounds $\mathbf{3 h}, \mathbf{3 o}, \mathbf{3 r}$ (Zone of inhibition 25), $\mathbf{3 b}, \mathbf{3 l}$ (Zone of inhibition 24) and $\mathbf{3 f}$ (Zone of inhibition 23) displayed good potency relative to ampicillin (Zone of inhibition 30).

Concerning the antifungal activity of tested compounds, compound $\mathbf{3 i}$ showed highest activity against F. oxysporum, i.e., Zone of inhibition 21, while three compounds namely $\mathbf{3 c}, \mathbf{3 j}$ and $\mathbf{3 p}$ (Zone of inhibition $20)$ exhibited good growth inhibitory action on $F$. oxysporum compared to the standard Griseofulvin (Zone of inhibition 26).

Analogue 3o (Zone of inhibition 25) showed chief inhibitory activity whereas $\mathbf{3 b}, \mathbf{3 g}, \mathbf{3 i}, \mathbf{3 p}$ (Zone of inhibition 24) and 3d (Zone of inhibition 23) produce good growth inhibitory activity against $A$. niger compared to the standard griseofulvin (Zone of inhibition 28). With regard to activity against Rhizopus oryzae, compounds 3a, 3e, 3h, 3k (Zone of inhibition 25), 3m (Zone of inhibition 24), 3q (Zone of inhibition 23) and $\mathbf{3 f}$ (Zone of inhibition 22) showed good activity compared to the standard griseofulvin (Zone of inhibition 30). Remaining compounds showed mild to moderate antifungal activity.

The data indicate that a change in the substituent might also affect the antibacterial activity of title compounds 3a-r. A close examination of the structures of the active compounds in table 1 revealed that, their antimicrobial activity is strongly bound to the nature of the substituent at the pyrazole together with the substituent linked to the naphthols part of the structure. It could be clearly recognized that potential antibacterial activity against Escherichia was encountered with 3k, $\mathbf{3} \mathbf{m}$ and $\mathbf{3 r}$. However, replacement of $\mathrm{R}_{1}=4-\mathrm{CH}_{3}$ in $\mathbf{3 k}$ with $\mathrm{H}$ (Compound $\mathbf{3 e}$ ) or 3-Cl (Compound $\mathbf{3 q}$ ) resulted in decrease in antibacterial activity. Replacement of $\mathrm{R}_{2}=\mathrm{Cl}$ in $\mathbf{3 k}$, i.e., electron-withdrawing group with electron-releasing group resulted in remarkable reduction in antibacterial spectrum. Against B. substilis, potential antibacterial activity was encountered with $\mathbf{3 f}$ and 3q. However, replacement of $\mathrm{R}_{1}=\mathrm{H}$ in $\mathbf{3 f}$ with 4- $\mathrm{CH}_{3}$ (Compound 3l) or 3-Cl (Compound 3r) showed marked decrease in antibacterial activity. Against $S$. aureus analogues $\mathbf{3 h}$ and $\mathbf{3 o}$ exhibited chief activity however replacement of $\mathrm{R}_{1}=4-\mathrm{CH}_{3}$ in $\mathbf{3 h}$ with $3-\mathrm{Cl}$ (Compound 3n) showed marked decrease in antibacterial activity. It also appears from antifungal activity data that compounds were more active towards $R$. oryzae and less active against $F$. oxysporum. Compounds which exhibited excellent activity towards $R$. oryzae compared to griseofulvin include $\mathbf{3 a}, \mathbf{3 e}, \mathbf{3 h}$ and $\mathbf{3 k}$. Replacement of $R_{2}$ with electron donating group in $\mathbf{3 a}$ (Compound $\mathbf{3 b}, \mathbf{3 c}$ and $\mathbf{3 d}$ ) resulted in marked decrease in antifungal activity.

\section{Conclusion}

In summary, we have successfully combined the advantages of microwave technology with multicomponent reactions to facilitate a competitive synthesis of 2amino- $4 H$-chromenes in ethanol. Particularly, valuable features of this method included the good to excellent yields and operational simplicity as well as increased safety for small-scale high-speed synthesis. This synthetic strategy allows the construction of relatively 
complicated nitrogen and oxygen containing fused heterocyclic system as well as introduction of various (hetero) aromatic substitutions into 4-position of chromene system. Most of the compounds showed better antibacterial activity. Further optimization and development is needed in designing more potent antibacterial and antifungal agents for therapeutic use. It is worth mentioning that minor change in molecular configuration of these compounds profoundly influences the activity.

\section{Acknowledgements}

We thank the Department of Chemistry, Sardar Patel University for providing research facilities. We also thank Vaibhav Analytical Laboratory, Ahmedabad for the FT-IR and Sophisticated Instrumentation Centre for Applied Research and Training (SICART), Vallabh Vidyanagar for elemental analysis and Oxygen Healthcare Research Pvt. Ltd., Ahmedabad for providing mass spectrometry facilities. NMS thank the University Grants Commision (UGC), New Delhi, India for a Research Fellowship in Sciences for Meritorious Students.

\section{Supplementary information}

The electronic supporting information can be seen in www.ias.ac.in/chemsci.

\section{References}

1. Domling A 2002 Curr. Opin. Chem. Biol. 6303

2. (a) Wender P A, Handy S T and Wright D L 1997 Chem. Ind. 765; (b) Trost B M 1995 Angew. Chem., Int Ed. Engl. 34259

3. (a) Terrett N K 1998 Combinatorial chemistry (New York: Oxford University Press); (b) Domling A 2006 Chem. Rev. 10617

4. Khafagy M M, El-Wahas A H F A, Eid F A and El-Agrody A M 2002 II Farmaco 57715

5. Smith W P, Sollins L S, Howes D P, Cherry C P, Starkey D I and Cobley N K 1998 J. Med. Chem. 41787

6. Martinez A G and Marck L J 1997 Bioorg. Med. Chem. Lett. 73165

7. Dell C P and Smith C W 1993 EP 537949 Chem. Abstr. $119139102 d$

8. Bianchi G and Tava A 1987 Agric. Biol. Chem. 512001

9. Mohr S J, Chirigios M A, Fuhrman F S and Pryor J W 1975 Cancer Res. 353750

10. Anderson D R, Hegde S, Reinhard E, Gomez L, Vernier W F, Lee L, Liu S, Sambandam A, Sinder P A and Masih L 2005 Bioorg. Med. Chem. Lett. 151587

11. Skommer J, Wlodkowic D, Matto M, Eray M and Pelkonen J 2006 Leukemia Res. 30322
12. Wang J L, Liu D, Zhang Z, Shan S, Han X, Srinvasula S M, Croce C M, Alnemeri E S and Huang Z 2000 Proc. Natl. Acad. Sci. USA. 977124

13. Eiden F and Denk F 1991 Arch. Pharm. Weinhein Ger. (Arch. Pharm.) 324353

14. (a) Hafez E A, Elnagdi M H, Elagamey A G A and ElTaweel F M A A 1987 Heterocycles 26 903; (b) Sofan M A, Elnagdi M H and ElTaweel F M A A 1989 Liebigs. Ann. Chem. 1989 935; (c) Varma R S and Dahiya R 1998 J. Org. Chem. 63 8038; (d) ElAgrody A M, ElHakiem M H, Abd El-Latif M S, Fakery A H, El-Sayed E S M and El-Ghareab K A 2000 Acta Pharm. 50111

15. (a) Tewari A K and Mishra A 2001 Bioorg. Med. Chem. 9 715; (b) Wiley R H and Wiley P 1964 Pyrazolones, pyrazolidones and derivatives (New York: John Wiley and Sons); (c) Pimerova, E V and Voronina E V $2001 \mathrm{~J}$. Pharm. Chem. 35 18; (d) Janus S L, Magdif A Z, Erik B P and Claus N 1999 Monatsh. Chem. 130 1167; (e) Park H J, Lee K, Park S, Ahn B, Lee J C, Cho H Y and Lee K I 2005 Bioorg. Med. Chem. Lett. 15 3307; (f) Michon V, Du Penhoat C H, Tombret F, Gillardin, J M, Lepagez F and Berthon L 1995 Eur. J. Med. Chem. 30 147; (g) Yildirim I, Özdemir N, Akçamur Y, Dinçer M and Andaç O 2005 Acta. Crystallogr. 61 256; (h) Bailey D M, Hansen P E, Hlavac A G, Baizman E R, Pearl J, Defelice A F and Feigenson M E 1985 J. Med. Chem. 28 256

16. Cheng H, Lundy DeMello K M, Li J, Sakya S M, Ando K, Kawamura K, Kato T, Rafka R J, Jaynes B H, Ziegler C B, Stevens R, Lund L A, Mann D W, Kilroy C, Haven M L, Nimz E L, Dutra J K, Li C, Minich M L, Kolosko N L, Petras C, Silivia A M and Seibel S B 2006 Bioorg. Med. Chem. Lett. 162076

17. Chowdhury M A, Abdellatif K R A, Dong Y, Das D, Suresh M R and Knaus E E 2008 Bioorg. Med. Chem. Lett. 186138

18. (a) Bose A K, Banik B K, Lavlinskaia N, Jayaraman M and Manhas M S 1997 Chemtech 27 18; (b) Caddick S 1995 Tetrahedron 5110403

19. Gedye R, Smith F, Westawaym K, Humera A, Baldisern L, Laberge L and Rousell J 1986 Tetrahedron Lett. 27 279

20. Shah N M, Patel M P and Patel R G 2012 J. Het. Chem. 491310

21. Shah N K, Shah N M, Patel M P and Patel R G 2012 J. Serb. Chem. Soc. 77(3) 279

22. (a) Mungra D C, Patel M P, Rajani D P and Patel R G 2011 Eur. J. Med. Chem. 46 4192; (b) Shah N K, Patel M P and Patel R G 2009 Phosphorus Sulfur Silicon and Relat. Elements 184 2704; (c) Makawana J A, Patel M P and Patel R G 2012 Med. Chem. Res. 21 616; (d) Mungra D C, Patel M P, Rajani D P and Patel R G 2009 Arkivoc xiv 64; (e) Sangani C B, Mungra D C, Patel M P and Patel R G 2011 Cent. Eur. J. Chem. 9635

23. Pawar R A and Patil A A 1994 Indian J. Chem. 33B 156

24. Collins C H and Lyne P M 1970 Microbial methods (Baltimore: University Park Press)

25. Thangadurai T D and Natarajan K 2001 Indian J. Chem. 40A 573 